ACCEPTED MANUSCRIPT

\title{
Structural phase transformations in annealed Pt/Mn/Fe trilayers
}

To cite this article before publication: Ivan Kruhlov et al $2020 \mathrm{~J}$. Phys.: Condens. Matter in press https://doi.org/10.1088/1361-648X/ab9269

\section{Manuscript version: Accepted Manuscript}

Accepted Manuscript is "the version of the article accepted for publication including all changes made as a result of the peer review process, and which may also include the addition to the article by IOP Publishing of a header, an article ID, a cover sheet and/or an 'Accepted Manuscript' watermark, but excluding any other editing, typesetting or other changes made by IOP Publishing and/or its licensors"

This Accepted Manuscript is @ 2020 IOP Publishing Ltd.

During the embargo period (the 12 month period from the publication of the Version of Record of this article), the Accepted Manuscript is fully protected by copyright and cannot be reused or reposted elsewhere.

As the Version of Record of this article is going to be / has been published on a subscription basis, this Accepted Manuscript is available for reuse under a CC BY-NC-ND 3.0 licence after the 12 month embargo period.

After the embargo period, everyone is permitted to use copy and redistribute this article for non-commercial purposes only, provided that they adhere to all the terms of the licence https://creativecommons.org/licences/by-nc-nd/3.0

Although reasonable endeavours have been taken to obtain all necessary permissions from third parties to include their copyrighted content within this article, their full citation and copyright line may not be present in this Accepted Manuscript version. Before using any content from this article, please refer to the Version of Record on IOPscience once published for full citation and copyright details, as permissions will likely be required. All third party content is fully copyright protected, unless specifically stated otherwise in the figure caption in the Version of Record.

View the article online for updates and enhancements. 


\title{
Structural phase transformations in annealed Pt/Mn/Fe trilayers
}

I. O. Kruhlov ${ }^{1}$, O. V. Shamis', N. Y. Schmidt' ${ }^{2}$ M.V. Karpets ${ }^{1}$, S. Gulyas ${ }^{3,4}$, E. Hadjixenophontos ${ }^{5,6}$, A. P. Burmak ${ }^{1}$, S. I. Sidorenko ${ }^{1}$, G. L. Katona ${ }^{3}$, G. Schmitz ${ }^{5}$, M. Albrecht ${ }^{2}$, and I. A. Vladymyrskyi ${ }^{1, *}$

${ }^{1}$ Metal Physics Department, National Technical University of Ukraine "Igor Sikorsky Kyiv Polytechnic Institute”, Prospect Peremogy 37, 03056 Kyiv, Ukraine

${ }^{2}$ Institute of Physics, University of Augsburg, Universitätsstraße 1, D-86159 Augsburg, Germany ${ }^{3}$ University of Debrecen, Faculty of Science and Technology, Department of Solid State Physics, P.O. Box 400, H-4002 Debrecen, Hungary

${ }^{4}$ University of Debrecen, Doctoral School of Physics, P.O. Box 400, H-4002Debrecen, Hungary ${ }^{5}$ University of Stuttgart, Department of Materials Science, Chair of Materials Physics, Heisenbergstrasse 3, D-70569, Stuttgart, Germany

${ }^{6}$ German Aerospace Center (DLR), Institute of Engineering Thermodynamics, High Temperature Systems and Process Development, Pfaffenwaldring 38-40, D-70569 Stuttgart, Germany

\author{
*Corresponding author \\ (e-mail: vladymyrskyi@kpm.kpi.ua)
}

\begin{abstract}
Thermally-activated phase transitions in $\mathrm{Pt} / \mathrm{Mn} / \mathrm{Fe}$ thin films were investigated by a combination of $\mathrm{x}$-ray diffraction, transmission/electron microscopy, secondary neutral mass spectrometry depth profiling, atomic force microscopy, and magnetic properties measurements. Postannealing was carried out in vacuum to different temperatures up to $620^{\circ} \mathrm{C}$. Initially, at temperatures between $280{ }^{\circ} \mathrm{C}-450{ }^{\circ} \mathrm{C}$ first $\mathrm{L}_{10} \mathrm{MnPt}$ is formed at the $\mathrm{Mn} / \mathrm{Pt}$ interface followed by the most likely formation of metastable bcc $\mathrm{Fe}_{3} \mathrm{Pt}$, which gets transformed by further annealing to fcc $\mathrm{Fe}_{3} \mathrm{Pt}$ and eventually to chemically ordered $L 1_{2}-\mathrm{Fe}_{3} \mathrm{Pt}$. The final product after annealing at $620^{\circ} \mathrm{C}$ consists of two interesting phases, which are relevant for spintronic applications, antiferromagnetic $L 1_{0}-\mathrm{MnPt}$ with addition of $\mathrm{Fe}$ and ferromagnetic $\mathrm{LI}_{2}-\mathrm{Fe}_{3} \mathrm{Pt}$, consistent with the initial element composition.
\end{abstract}

Key words: chemical ordering, solid state reactions, magnetic thin films, $L 1_{0}-\mathrm{MnPt}, L 1_{0}-\mathrm{FeMnPt}$, $\mathrm{Fe}_{3} \mathrm{Pt}$ 


\section{Introduction}

Structural phase formation induced by thermally-activated diffusion processes and intermixing of multilayer stacks is a promising reaction pathway for synthesis of novel thin film materials. In particular, the sequence of structural phase transitions in layered structures during annealing could differ from those predicted by corresponding bulk phase diagrams due to sufficient deviation from thermodynamic equilibrium. For instance, thermally-activated diffusion intermixing in $\mathrm{Cu} / \mathrm{Sn}$ bilayers, which are relevant for nano-electronic applications, can lead to the formation of different metastable phases. Annealing at $100{ }^{\circ} \mathrm{C}$ of the $\mathrm{Cu}(80 \mathrm{~nm}) / \mathrm{Sn}(20 \mathrm{~nm})$ stack leads to formation of the $\mathrm{Cu}_{3} \mathrm{Sn}$ phase and following annealing at $200{ }^{\circ} \mathrm{C}$ leads to the unexpected formation of the metastable $\mathrm{Cu}_{4} \mathrm{Sn}$ phase, which should be formed at temperatures higher than $350^{\circ} \mathrm{C}$, according to the $\mathrm{Cu}-\mathrm{Sn}$ bulk phase diagram. This phenomenon was explained based on the Ostwald's rule of growth stages, stating that a system being far from equilibrium approaches the equilibrium state with steps, involving the minimum change of the free energy rather than reaching the equilibrium directly [1]. In this regard, various factors such as layer stacking [2-4], annealing conditions [5-7], or substrate choice [8-10] will strongly affect the development of diffusion processes and phase formation

Numerous theoretical [11-14] and expérimental/[15-18] studies of diffusion and phase transformations of materials that are of particular interest for applications in spintronics and data storage, are available in the literature. For instance, post-annealing of Pt/Fe bilayers at relatively lowtemperatures, which ensure diffusion processes limited to grain boundary mechanisms, could lead to full homogenization of chemical composition throughout the film or even to $L 1_{0}$ chemical ordering $[19,20]$. In this process, phase formation occurs via the movement of grain boundaries as a result of grain boundary diffusion, leaving behind an area of reacted product [21]. Furthermore, introduction of additional intermediate layers into $\mathrm{Pt} / \mathrm{Fe}$ stacks could modify significantly the phase transition temperatures [20, 22-24], the sequence of structural transitions that occur upon annealing [25], or even induce metastable phases [26]. In this regard, $\mathrm{Mn}$ is an interesting element to be used as an additional layer in Fe/Pt stacks since it could form various binary and ternary phases in this system and strongly affect the magnetic properties due to antiferromagnetic coupling between Fe and $\mathrm{Mn}$ magnetic moments. Early investigations of the bulk FeMnPt phase diagram [27] revealed that in $\left(\mathrm{Fe}_{1-\mathrm{x}} \mathrm{Mn}_{\mathrm{x}}\right) \mathrm{Pt}$ phases for an intermediate concentration of $\mathrm{Mn}(\mathrm{x}=0.2-0.45)$ there are two stable phases present ferromagnetic $L 1_{0}-\mathrm{FePt}$ and antiferromagnetic $L 1_{0}-\mathrm{MnPt}$. However, most of available studies are related to alloyed thin films of the quasi-binary $\left(\mathrm{Fe}_{1-\mathrm{x}} \mathrm{Mn}_{\mathrm{x}}\right)_{50} \mathrm{Pt}_{50}$ composition [27-33]. As reported by Crisan et al. [34], annealing of FeMnPt films with various Mn content at $500{ }^{\circ} \mathrm{C}$ for 1 hour resulted in a multiphase structure: $L 1_{0}-\mathrm{FePt}, L 1_{0}-\mathrm{FeMnPt}$, and a small amount of bcc-Fe. Moreover, 
Chiang et al. [35] obtained a graded elemental distribution through the depth of $\mathrm{FePt}(25 \mathrm{~nm}) / \mathrm{PtMn}(50 \mathrm{~nm})$ films when deposited at $500{ }^{\circ} \mathrm{C}$ on $\mathrm{MgO}(001)$ followed by post-annealing at $550{ }^{\circ} \mathrm{C}$. However, the evolution of phase formation during annealing of the layer stacks was not addressed.

In this study, the various stages of structural phase formation and composition occurring in $\mathrm{Pt} / \mathrm{Mn} / \mathrm{Fe}$ trilayers upon annealing to different temperatures up to $620^{\circ} \mathrm{C}$ were investigated by a combination of various techniques including x-ray diffraction, transmission electron microscopy, and secondary neutral mass spectrometry depth profiling. In addition, magnetic studies were performed in order to get further evidence for the proposed phase transformations.

\section{Experimental details}

$\operatorname{Pt}(15 \mathrm{~nm}) / \mathrm{Mn}(7.5 \mathrm{~nm}) / \mathrm{Fe}(15 \mathrm{~nm}) / \mathrm{sub}$. thin films were deposited by dc magnetron sputtering at room temperature on thermally oxidized $\mathrm{Si}(100)$ substrates with a $100 \mathrm{~nm}$-thick amorphous $\mathrm{SiO}_{2}$ layer using individual Fe (99.99\%), Pt (99.99\%), and Mn (99.95\%) targets. The sputtering powers for $\mathrm{Pt}, \mathrm{Fe}$, and Mn were $45 \mathrm{~W}, 98 \mathrm{~W}$, and $91 \mathrm{~W}$, resulting in sputtering rates of $0.47 \AA / \mathrm{s}, 0.36 \AA / \mathrm{s}$, and $0.2 \AA / s$, respectively. All depositions were carried out in a BESTEC UHV sputter system (base pressure of $<5 \times 10^{-6} \mathrm{~Pa}$ ) using an Ar sputter pressure of $0.5 \mathrm{~Pa}$. Sputtering rates were checked by a quartz crystal microbalance before each deposition. In Fig. 1, a cross-section transmission electron microscopy (TEM) image of the as-deposited Pt/Mn/Fe layer stack is shown confirming the layered structure and layer thicknesses of the prepared film. These as-deposited films were annealed in the temperature range of $155-620^{\circ} \mathrm{C}$ in vacuum $\left(10^{-3} \mathrm{~Pa}\right)$ with an average heating rate of $0.5^{\circ} \mathrm{C} / \mathrm{s}$. The film temperature during annealing was measured directly at the film top surface by K-type thermocouples. After reaching the final film temperature, the sample holder was removed from the heating stage by a specially adapted lever without breaking the vacuum. 


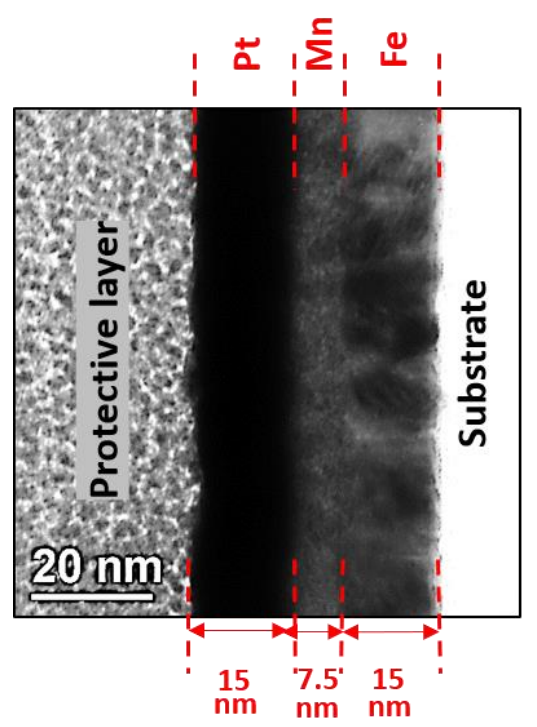

Figure 1. Cross-section TEM image of the as-deposited Pt/Mn/Fe film sample.

The structure and phase composition of the $\mathrm{Pt} / \mathrm{Mn} / \mathrm{Fe}$ film samples after different annealing conditions were analyzed at room temperature by $\mathrm{x}$-ray diffraction (XRD) in $(\theta-2 \theta)$ geometry using a Rigaku Ultima IV diffractometer with $\mathrm{Cu}-\mathrm{K}_{\alpha}$ radiation. XRD scans were refined according to Rietveld's full profile approach using the PowderCell 2.4 software [36]. Profiles of diffraction peaks were fitted by a pseudo-Voight function. Quantitative estimation of phase composition was performed taking into account the presence of phase textures according to the March-Dollase model [37]. In this model, the correction of the intensity of any diffraction peak is realized by introducing an effective repetition factor. In case, the investigated phase does not reveal texture, the texture coefficient is equal to 1 , and if all grains are oriented in the same direction this coefficient gets zero, while in intermediate cases it takes values between 1 and 0 . Since some of the obtained XRD scans show second order harmonic reflection from the $\mathrm{Si}(400)$ plane, the angle interval of $32.2^{\circ}-38^{\circ}$ was excluded from Rietveld's analysis. Finally, the following parameters were refined by Rietveld's approach: lattice constants, relative phase abundance, function parameters of diffraction maximums, parameters of sample shift from zero value and coefficient of 7-order polynomial for background description. Weight R-factor $\left(R_{w t}\right)$ and expected R-factor $\left(R_{\exp }\right)$ discrepancy indexes of Rietveld's analysis were calculated using the standard methodology [38]. In addition, the goodness of the Rietveld's fit $\left(\chi^{2}\right)$ was estimated as the ratio of $\left(R_{w t} / R_{\text {exp }}\right)^{2}$. The profile refinement is considered as perfect when $\chi^{2}$ is equal to 1 , while the goodness decreases for larger values.

Furthermore, secondary neutral mass spectrometry (SNMS, INA-X system, SPECS GmbH) depth profiling was carried out in order to follow the changes in the elemental distribution through the film depth. For the SNMS experiments, Ar plasma was used as a source of bombarding positive ions 


\section{Results and discussion}

XRD $(\theta-2 \theta)$ scans of the sample series after different post-annealing treatments are summarized in Fig. 2 and 3. Starting with the as-deposited film (Fig. 2a), only reflections originating from face-centered cubic (fcc) Pt and body-centered cubic (bcc) Fe are observed while Mn seems to appear most likely XRD amorphous. Absence of Mn peaks on the XRD patterns could be caused by its fine grain structure consisting of the complex cubic $\alpha-M n$ phase [39]. The SNMS depth profile of the as-deposited film (Fig. 4a) suggests relatively sharp interfaces of the layer stack, as confirmed by corresponding TEM imaging (Fig. 1).

First notable changes in XRD patterns and elemental distribution through the film depth compared to the as-deposited sample are observed for the sample annealed at $280{ }^{\circ} \mathrm{C}$. As can be seen in the corresponding depth profile (Fig. 4c), intensive intermixing between $\mathrm{Mn}$ and Pt layers is present. XRD measurements (Fig. 2c) confirm the formation of the polycrystalline chemically ordered $L 1_{0^{-}}$ MnPt phase with pronounced (001), (002), and (110) reflections. Based on the initial layer thicknesses of the as-deposited $\mathrm{Pt} / \mathrm{Mn} / \mathrm{Fe}$ sample, the elemental concentrations in a fully mixed system would give 34 at. $\% \mathrm{Pt}, 21$ at. $\% \mathrm{Mn}$, and 45 at.\% Fe. Thus, Mn and Pt can be almost fully consumed in the $\mathrm{L1}_{0^{-}}$ MnPt phase, assuming a maximal Pt content of 60 at.\% (according to the phase diagram [40, 41]). In addition, a pronounced Mn segregation towards the film surface was detected by depth profiling. It should be noted that due to the high affinity of Mn to oxygen [29], oxidation of this surface segregation layer is expected [31]. 
Annealing up to $400{ }^{\circ} \mathrm{C}$ did not result in a significant change in crystal structure except of a slight shift of the Fe(110) reflection towards lower $2 \theta$ angles (Fig. 2d). This shift could indicate the initial formation of a Fe-rich solid solution with $\mathrm{Pt}$ as a result of bcc lattice expansion due to partial substitution of Fe sides by the larger Pt atoms [42].

After further increase of the annealing temperature to $450{ }^{\circ} \mathrm{C}$, the XRD pattern shown in Fig. 2e reveals the appearance of an additional diffraction peak at $2 \theta=43.07^{\circ}$ which could originate from $\gamma$ FeMn(111), a non-coplanar antiferromagnet at room temperature [43] or more likely to the formation of the metastable bcc $\mathrm{Fe}_{3} \mathrm{Pt}$ phase [42]. The corresponding SNMS depth profile supports this assumption by the observation of a moderate penetration of $\mathrm{Pt}$ and $\mathrm{Mn}$ into the Fe layer (Fig. 4f), yet the concentration distribution does not correspond to the equiatomic FeMn phase favoring the presence of bcc $\mathrm{Fe}_{3} \mathrm{Pt}$. However, SNMS profiling has limits as an integral method, giving only average values over a sample area without lateral resolution. Therefore, film roughness will drastically affect and limit the depth resolution. In this regard, AFM imaging was performed on the sample series at room temperature showing a severe increase in route mean square (rms) roughness for samples annealed above $400{ }^{\circ} \mathrm{C}$ (Fig. 5). Thus, SNMS data need to be considered with caution as the results at these temperatures are not reliable.

In order to get more information on the present phases occurring for the film annealed at $450{ }^{\circ} \mathrm{C}$, EDX spectra were measured at different locations of the prepared TEM lamella (Fig. 6a,b). Near the surface, a high concentration of $\mathrm{Mn}$ and $\mathrm{Pt}$ was detected (grains 1 and 2), which is in agreement with depth profiles and XRD results confirming the presence of the $L 1_{0}-\mathrm{MnPt}$ phase, while the bottom layer close to the substrate (grains 3 and 4) consists mainly of Fe along with $\mathrm{Pt}$ and $\mathrm{Mn}$ supporting the presence of the $\mathrm{Fe}_{3} \mathrm{Pt}$ phase.

With further increase of the annealing temperature up to $500{ }^{\circ} \mathrm{C}$, the XRD intensity of the $L 1_{0^{-}}$ $\mathrm{MnPt}$ reflections gets more pronounced (Fig. 2f). It is suggested that Fe further diffuses towards the surface and gets incorporated into the $L 1_{0}$ structure. Therefore, it is concluded that a $L 1_{0}-\mathrm{FeMnPt}$ ternary alloy is formed, which remains antiferromagnetic due to the low Fe content. Interestingly, the bcc $\mathrm{Fe}_{3} \mathrm{Pt}$ reflection has almost vanished but shifted to lower angles (at $2 \theta \approx 41.9^{\circ}$, Fig. 1f) indicating the transition to the fcc $\mathrm{Fe}_{3} \mathrm{Pt}$ structure which transforms into chemically ordered $\mathrm{LI}_{2}-\mathrm{Fe}_{3} \mathrm{Pt}$ upon further annealing. Please note that the (111) reflections of the two $\mathrm{Fe}_{3} \mathrm{Pt}$ structures, fcc and $\mathrm{LI}_{2}$, are almost identical, but it is expected that beyond $500{ }^{\circ} \mathrm{C}$ the chemically ordered phase is more favored [42]. Temperature increase above $500{ }^{\circ} \mathrm{C}$ leads to a broadening of the (111) peak of the $L 1_{0^{-}}$ $\mathrm{FeMnPt}$ phase and to a pronounced intensity enhancement of the (111) reflection of the $\mathrm{Fe}_{3} \mathrm{Pt}$ phase, indicating changes of the texture parameters and grain size of these phases under temperature increase. 
The presence of these two phases is consistent with the initial elemental composition of 34 at.\% Pt, 21 at.\% Mn, and 45 at.\% Fe. Assuming that all $\mathrm{Mn}$ is consumed in the equiatomic $21_{0}-\mathrm{MnPt}$ phase with a slight amount of $\mathrm{Fe}$ and some $\mathrm{Mn}$ at the surface, the remaining Pt and Fe have a ratio of about $1: 3$ resulting in the $L 1_{2}-\mathrm{Fe}_{3} \mathrm{Pt}$ phase.

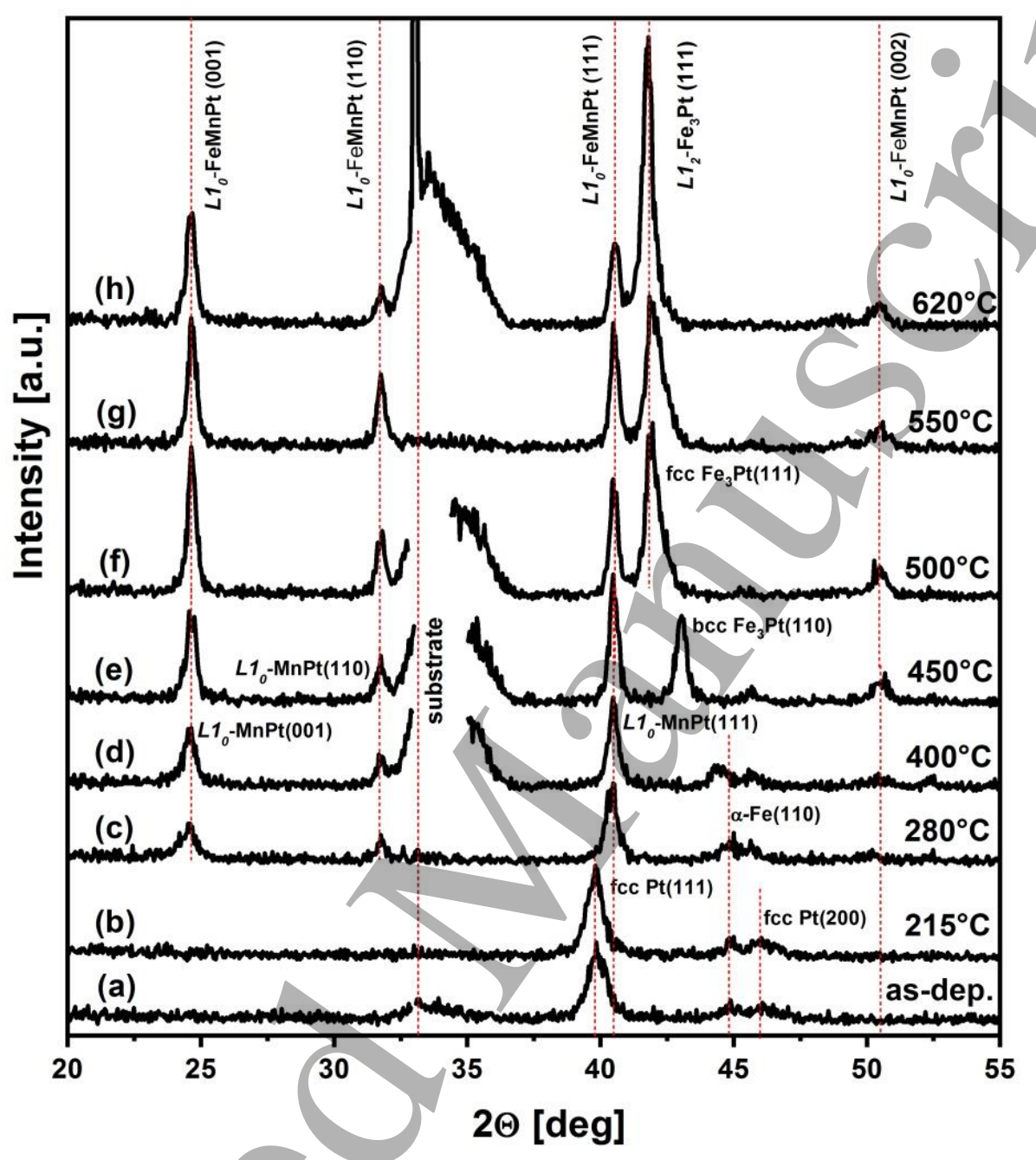

Figure 2. (a-h) XRD $(\theta-2 \theta)$ scans of $P t(15 \mathrm{~nm}) / \mathrm{Mn}(7.5 \mathrm{~nm}) / \mathrm{Fe}(15 \mathrm{~nm})$ films after deposition and post-annealing at different temperatures. 

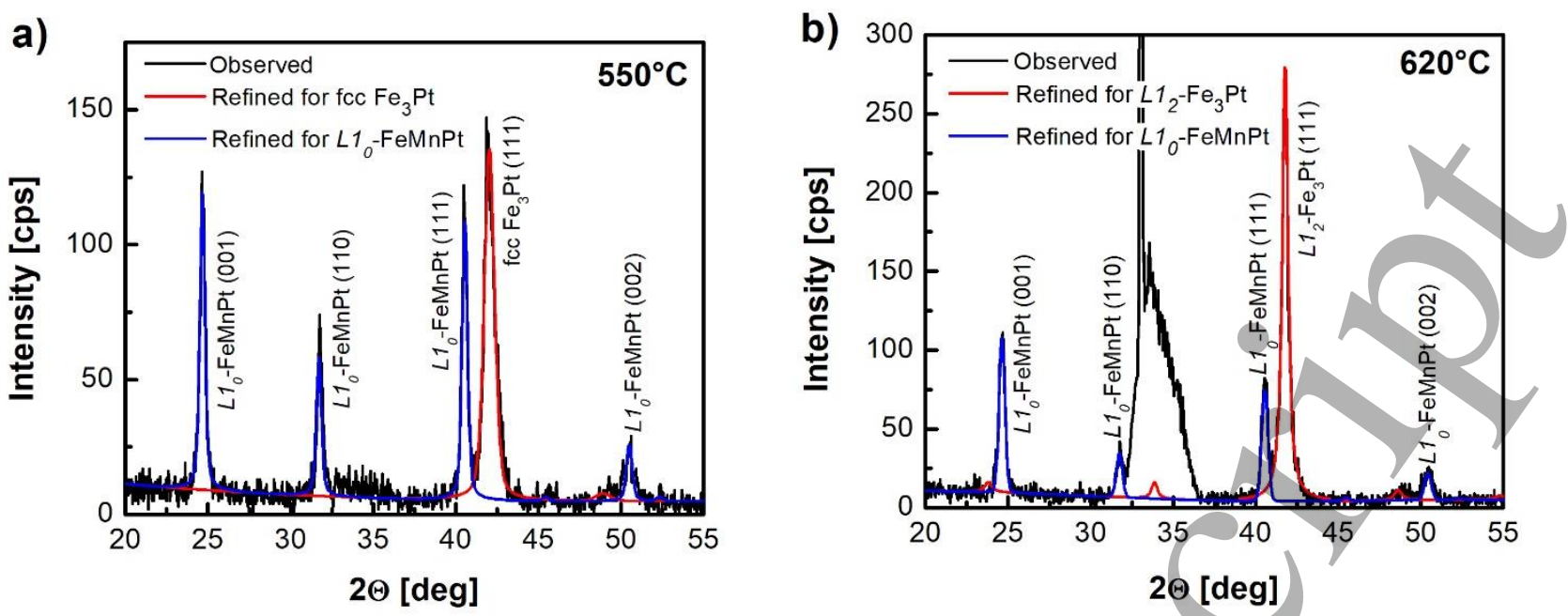

Figure 3. XRD patterns of $\operatorname{Pt}(15 \mathrm{~nm}) / \mathrm{Mn}(7.5 \mathrm{~nm}) / \mathrm{Fe}(15 \mathrm{~nm})$ films post-annealed at $550{ }^{\circ} \mathrm{C}$ (a) and $620^{\circ} \mathrm{C}$ (b). In addition, the refined diffractograms applying Rietveld's analysis are included. In case of (b) the angle interval of 32.2 - 38 degrees was excluded from refinement.

Application of Rietveld's full profile fitting allowed to refine the lattice parameters $(a$ and $c)$, relative concentrations (in mass \%), and the texture coefficients of different phases formed after various heat treatment stages. The results are summarized in table 1 giving the relevant parameters of the samples after various heat treatment stages. As an example, diffractograms including refined patterns of films annealed at $550{ }^{\circ} \mathrm{C}$ and $620^{\circ} \mathrm{C}$ are shown in Fig. $3 \mathrm{a}$ and b, respectively.

The estimation of relative phase concentrations was performed for films annealed above $400{ }^{\circ} \mathrm{C}$, where the coexistence of different phases became substantial. The evolution of $\mathrm{Fe}_{3} \mathrm{Pt}$ phases with different crystal lattices starting from bcc $\mathrm{Fe}_{3} \mathrm{Pt}\left(450^{\circ} \mathrm{C}\right)$ to $\mathrm{L1}_{2}-\mathrm{Fe}_{3} \mathrm{Pt}\left(620^{\circ} \mathrm{C}\right)$ caused a reduction of the $L 1_{0}$-FeMnPt amount from 65 to 55 mass.\%, respectively. According to the XRD refined data, the final product consists of 55 mass. $\%$ of $L 1_{0}-\mathrm{FeMnPt}$ and 45 mass.\% of $L 1_{2}-\mathrm{Fe}_{3} \mathrm{Pt}$ phases. Furthermore, the presence of preferential grain orientation was investigated by analyzing the texture coefficients $\tau$. A tendency of increment in number of grains with $\{001\}$ orientation was detected for the $L 1_{0^{-}}(\mathrm{Fe}) \mathrm{MnPt}$ tetragonal phase, which reflected in the decrease of $\tau 001$ values with increasing the heat treatment temperature up to $500{ }^{\circ} \mathrm{C}$. The following increase of treatment temperature does not lead to sufficient changes in texture parameter. Simultaneously, dominant $\{111\}$ texture was revealed in both $\mathrm{Fe}_{3} \mathrm{Pt}$ cubic phases starting from $500{ }^{\circ} \mathrm{C}$. Moreover, a subsequent decrease of the lattice constants of the $\mathrm{L1}_{0}$ - FeMnPt phase upon annealing above $450^{\circ} \mathrm{C}$ was obtained which is additionally supporting the hypothesis of $\mathrm{Fe}$ incorporation into the already formed $L 1_{0}-\mathrm{MnPt}$ ordered structure.

Table 1. Evolution of structural properties - a and $c$ lattice constants (Å), relative concentration ( $M$ in mass \%), texture coefficients $(\tau)$ - of phases formed after various heat treatment 
stages (values in brackets provide absolute errors). In addition, the Rietveld's refinement discrepancy indexes (weight $R$-factor $\left(R_{w t}\right)$, expected $R$-factor $\left.\left(R_{\text {exp }}\right), \chi^{2}\right)$ are given.

\begin{tabular}{|c|c|c|c|c|c|c|c|c|c|}
\hline Phase & & as-dep. & $215^{\circ} \mathrm{C}$ & $280^{\circ} \mathrm{C}$ & $400^{\circ} \mathrm{C}$ & $450{ }^{\circ} \mathrm{C}$ & $500{ }^{\circ} \mathrm{C}$ & $550^{\circ} \mathrm{C}$ & $620^{\circ} \mathrm{C}$ \\
\hline $\mathrm{Pt}$ & $a$ & $3.920(7)$ & $3.930(5)$ & & & & & & \\
\hline$\alpha-\mathrm{Fe}$ & $a$ & $2.859(9)$ & $2.859(8)$ & $2.867(7)$ & $2.886(7)$ & & & & \\
\hline$L 1_{0}-\mathrm{MnPt}$ & $\begin{array}{c}a \\
c \\
\tau_{001}\end{array}$ & & & $\begin{array}{c}2.829(4) \\
3.644(6) \\
0.79\end{array}$ & $\begin{array}{c}2.826(3) \\
3.634(3) \\
0.71\end{array}$ & & & & \\
\hline$L 1_{0}-\mathrm{FeMnPt}$ & $\begin{array}{c}a \\
c \\
\tau_{001} \\
M \\
\end{array}$ & & & & & $\begin{array}{c}2.831(3) \\
3.625(4) \\
0.68 \\
65(7) \\
\end{array}$ & $\begin{array}{c}2.830(3) \\
3.620(4) \\
0.60 \\
52(6)\end{array}$ & $\begin{array}{c}2.827(2) \\
3.619(3) \\
0.67 \\
51(6)\end{array}$ & \begin{tabular}{|c|}
$2.825(3)$ \\
$3.624(4)$ \\
0.65 \\
$55(6)$ \\
\end{tabular} \\
\hline bcc $\mathrm{Fe}_{3} \mathrm{Pt}$ & $\begin{array}{l}a \\
M\end{array}$ & & & & & $\begin{array}{c}2.977(5) \\
35(7)\end{array}$ & & & \\
\hline $\mathrm{fcc} \mathrm{Fe}_{3} \mathrm{Pt}$ & $\begin{array}{c}a \\
\tau_{111} \\
M\end{array}$ & & & & & & $\begin{array}{c}3.734(6) \\
0.45 \\
48(6)\end{array}$ & $\begin{array}{c}3.727(5) \\
0.46 \\
49(6) \\
\end{array}$ & \\
\hline$L 1_{2}-\mathrm{Fe}_{3} \mathrm{Pt}$ & $\begin{array}{c}a \\
\tau_{111} \\
M\end{array}$ & & & & & & & & $\begin{array}{c}3.750(6) \\
0.35 \\
45(6)\end{array}$ \\
\hline & $\begin{array}{l}R_{\mathrm{wp}} \\
R_{\exp } \\
\chi^{2}\end{array}$ & $\begin{array}{c}4.7 \\
4.3 \\
1.195\end{array}$ & $\begin{array}{c}3.9 \\
3.8 \\
1.053\end{array}$ & $\begin{array}{c}3.8 \\
3.7 \\
1.055\end{array}$ & $\begin{array}{c}6.4 \\
2.8 \\
5.225\end{array}$ & $\begin{array}{l}6.2 \\
2.5 \\
6.15\end{array}$ & $\begin{array}{l}6.1 \\
2.4 \\
6.46\end{array}$ & $\begin{array}{c}4.2 \\
3.2 \\
1.72\end{array}$ & $\begin{array}{c}6.7 \\
2.5 \\
7.18\end{array}$ \\
\hline
\end{tabular}

The estimated values of the $\chi^{2}$ parameter are close to 1 for the as-deposited film and samples post-annealed at $215^{\circ} \mathrm{C}, 280^{\circ} \mathrm{C}$, and $550^{\circ} \mathrm{C}$, suggesting very high accuracy of Rietveld's refinement. For the other samples the $\chi^{2}$ parameter is larger than 1 but still suggesting reasonable correctness of the Rietveld's fitting. The difference is mainly caused by the presence or absence of the $\operatorname{Si}(400)$ reflection on the observed XRD patterns.

To summarize, from the structural and chemical analysis based on XRD, SNMS, and TEM results, the following sequence of the main phase transformations with annealing temperature can be proposed: $\mathrm{Pt} / \mathrm{Mn} / \mathrm{Fe} \stackrel{280^{\circ} \mathrm{C}}{\Longrightarrow} L 1_{0}-\mathrm{MnPt}+\alpha-\mathrm{Fe} \stackrel{450^{\circ} \mathrm{C}}{\Longrightarrow} L 1_{0}-\mathrm{FeMnPt}+$ bcc $\mathrm{Fe}_{3} \mathrm{Pt} \stackrel{500^{\circ} \mathrm{C}}{\Longrightarrow} L 1_{0}-\mathrm{FeMnPt}+$ $\mathrm{fcc} \mathrm{Fe}_{3} \mathrm{Pt} \stackrel{620^{\circ} \mathrm{C}}{\Longrightarrow} L 1_{0}-\mathrm{FeMnPt}+L 1_{2}-\mathrm{Fe}_{3} \mathrm{Pt}$. 


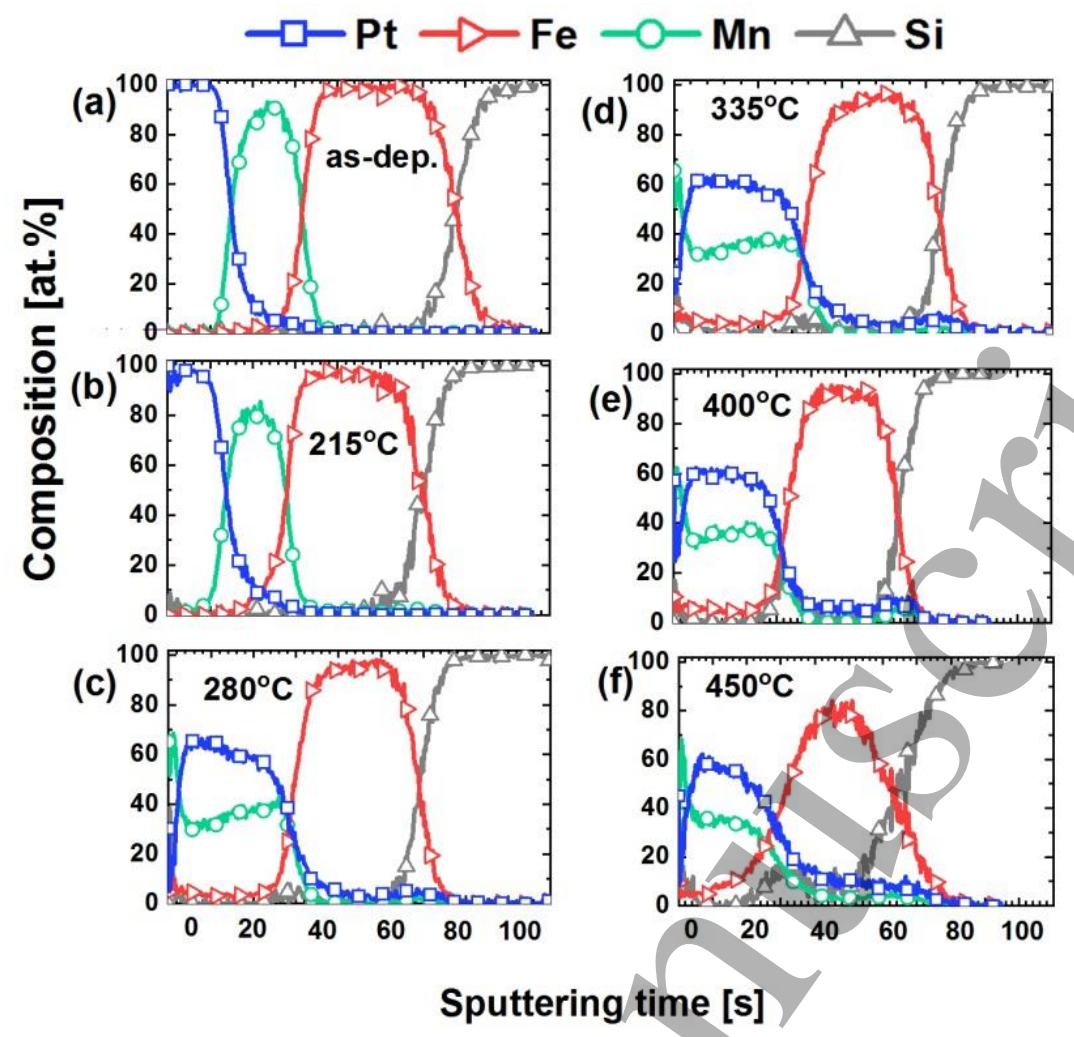

Figure 4. (a-h) SNMS composition-depth profiles of Pt/Mn/Fe films after deposition and postannealing at different temperatures. 
(a)

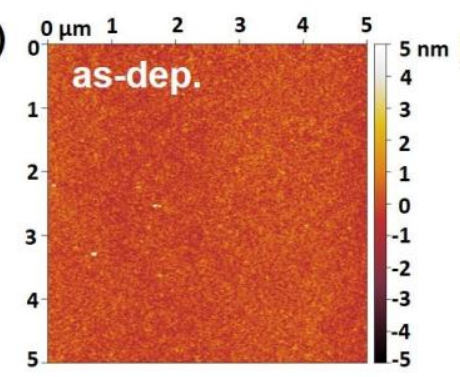

(c)
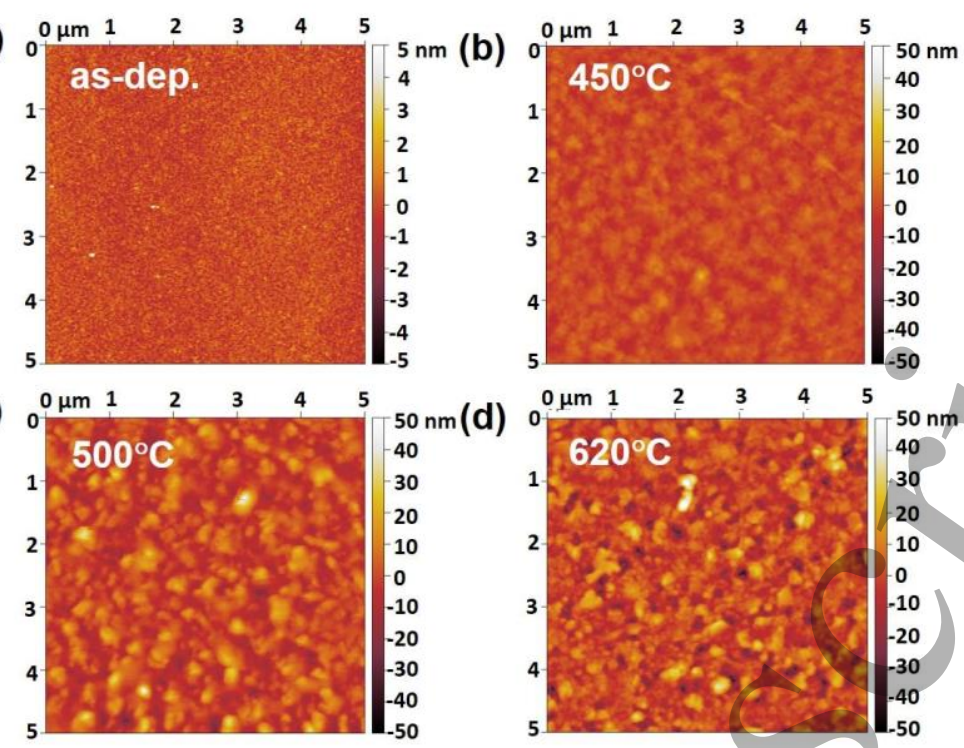

(e)

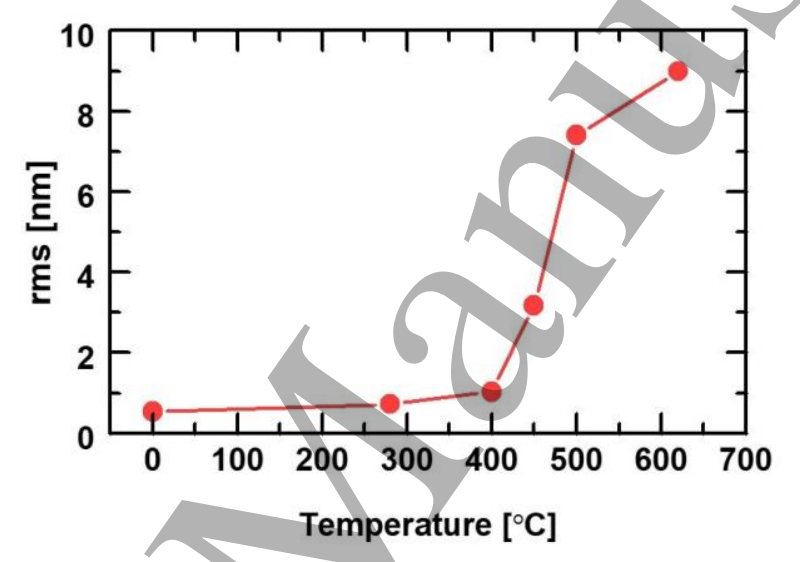

Figure 5. AFM images of the (a) as-deposited and $(b-d)$ annealed Pt/Mn/Fe film samples taken at room temperature. (e) Corresponding rms roughness in as-deposited state (" $0{ }^{\circ} \mathrm{C}$ ") and after annealing at different temperatures.

(a)

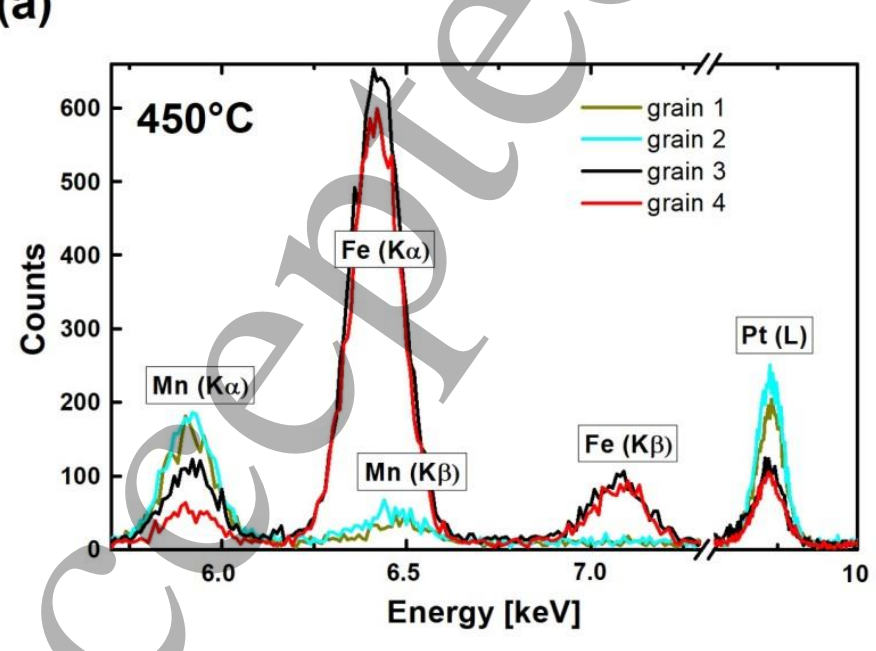

(b)

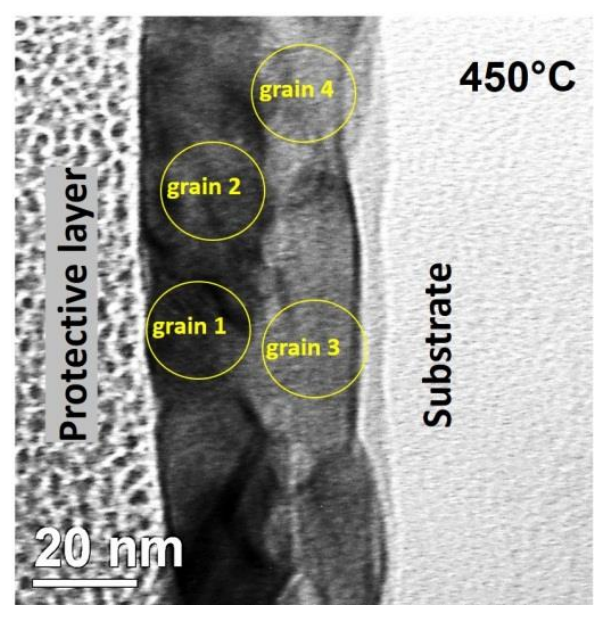

Figure 6. (a) EDX spectra and (b) corresponding cross-section TEM image of a $450^{\circ} \mathrm{C}$ post-annealed sample. EDX spectra were taken at specific locations of the TEM lamella as marked in (b). 
Magnetic studies are very useful in order to get further evidence for the proposed phase transformations. Therefore, magnetic $M$ - $H$ hysteresis loops in in-plane and out-of-plane geometry (Fig. 7a-e) were measured at room temperature to extract the in-plane coercivity $H_{\mathrm{c}}$ (Fig. 7f) and saturation magnetization $M_{\mathrm{s}}$ (Fig. 7h). For the latter, only the volume of the full initial layer stack was considered. Therefore, the $M_{\mathrm{s}}$ values reveal only relative changes upon phase formation and cannot be compared to material specific $M_{\mathrm{s}}$ values. All films clearly show an easy axis of magnetization in the film plane. As expected, no pronounced change in magnetic properties for samples annealed up to $400^{\circ} \mathrm{C}$ were observed, indicating a rather unaffected Fe layer with an in-plane easy axis of magnetization due to magnetic shape anisotropy. Above $400{ }^{\circ} \mathrm{C}$, there is a continuous decrease in magnetization, which indicates the incorporation of $\mathrm{Fe}$ into the $L 1_{0}-\mathrm{MnPt}$ lattice, compensating the magnetic moment of $\mathrm{Fe}$. Please note the additionally formed bcc $\mathrm{Fe}_{3} \mathrm{Pt}$ phase is expected to be ferromagnetic at room temperature exhibiting a rather high $M_{\mathrm{S}}$ value $\left(1530 \mathrm{emu} / \mathrm{cm}^{3},[42]\right)$, thus this phase cannot be the origin of the reduction in magnetization. However, the maximum in coercivity at $450{ }^{\circ} \mathrm{C}$ might be related to strong domain wall pinning effects at the bcc $\mathrm{Fe}_{3} \mathrm{Pt}$ grain boundaries and increased magnetic anisotropy. Furthermore, the structural transition of bcc $\mathrm{Fe}_{3} \mathrm{Pt}$ into fcc $\mathrm{Fe}_{3} \mathrm{Pt}$, which is expected to be in a paramagnetic state at room temperature [44], explains the lowering in coercivity and in magnetization which reveals a minimum after annealing at $500{ }^{\circ} \mathrm{C}$, the temperature where fcc $\mathrm{Fe}_{3} \mathrm{Pt}$ is dominantly formed. The residual magnetization might be due to some Fe remains and onset of $L 1_{2^{-}}$ $\mathrm{Fe}_{3} \mathrm{Pt}$ formation. Further rise of annealing temperature up to $620^{\circ} \mathrm{C}$ results in the favored development of ferromagnetic $L 1_{2}-\mathrm{Fe}_{3} \mathrm{Pt}$ phase with rather high $M s$ value (1270 emu/cm ${ }^{3}$ [42]) accompanied by the evolution of antiferromagnetic $L 1_{0}$-FeMnPt phase and changes of its phase content, together causing a strong increase in saturation magnetization. It should be pointed out, that since all mentioned phase transitions are not sharp and the coexistence of phases with different magnetic properties is present, the magnetization from each phase cannot be extracted from the total magnetization of the stack. Thus, the interpretation of temperature dependence of magnetic properties should only be accompanied with the results from the structural and chemical measurements.

In order to provide additional evidence for the presence of a paramagnetic fcc $\mathrm{Fe}_{3} \mathrm{Pt}$ phase, the saturation magnetization was analyzed in dependence of the temperature for three samples postannealed to $450{ }^{\circ} \mathrm{C}, 500^{\circ} \mathrm{C}$, and $550^{\circ} \mathrm{C}$ (Fig. $7 \mathrm{~g}$ ). While the sample prepared at $450{ }^{\circ} \mathrm{C}$ containing only ferro- and antiferromagnetic phases showed almost no temperature dependence, the other two samples revealed a pronounce increase at lower temperatures which hint to paramagnetic contributions complemented with a broad distribution of magnetic ordering temperatures. However, due to the magnetic background signal of the substrate, which is difficult to subtract, unequivocal conclusion cannot be made. 

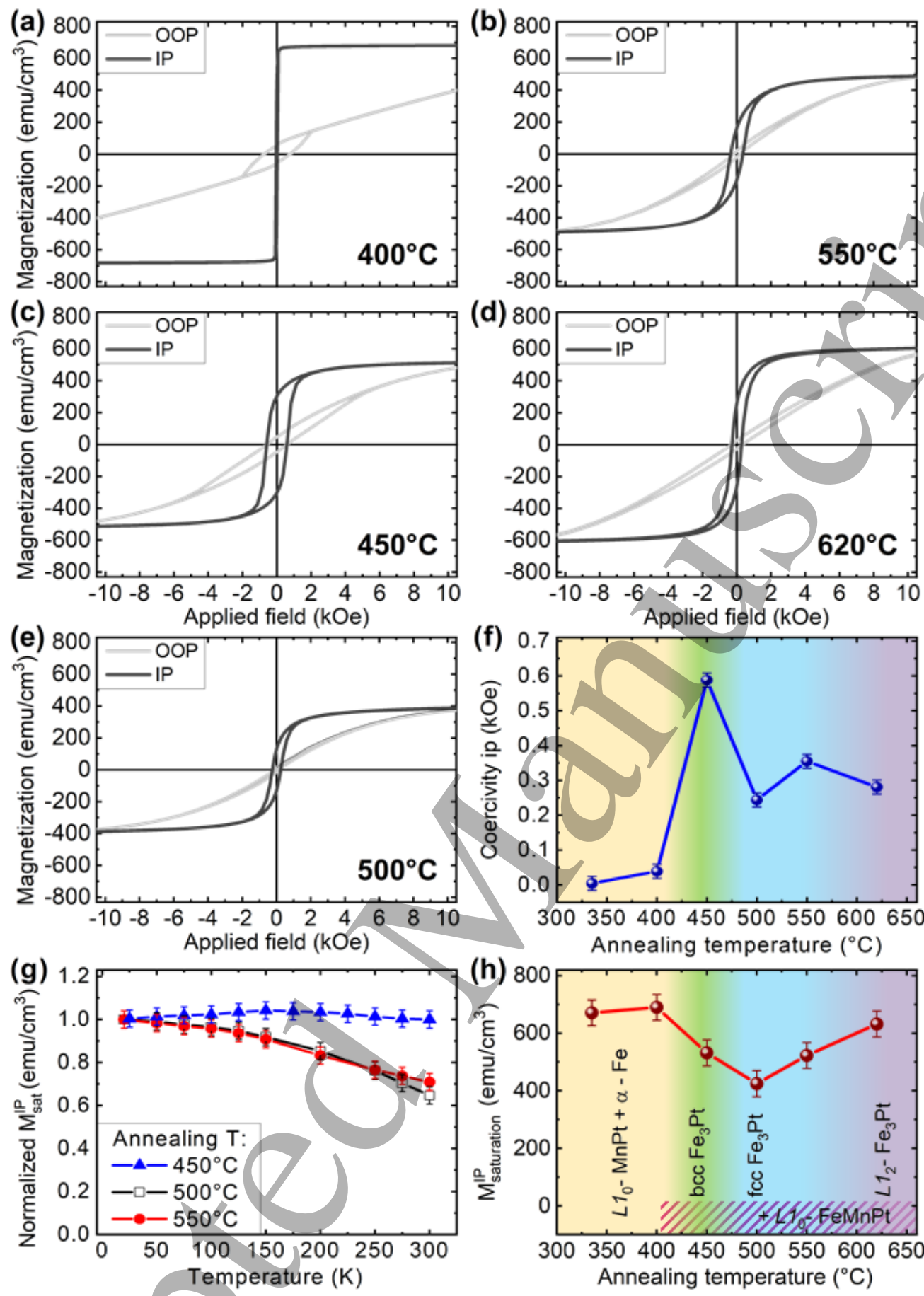

Figure 7. (a-e) In-plane and out-of-plane M-H hysteresis loops of Pt/Mn/Fe films after deposition and post-annealing at different temperatures. (f) Coercivity (from in-plane loops) and $(h)$ saturation magnetization at room temperature as function of annealing temperature. $(g)$ Normalized saturation magnetization as function of temperature for three samples post-annealed at different temperatures. 


\section{Conclusion}

The sequence of phase transitions occurring in $\mathrm{Pt} / \mathrm{Mn} / \mathrm{Fe}$ trilayers during post-annealing in vacuum up to $620{ }^{\circ} \mathrm{C}$ was investigated. After annealing at $280^{\circ} \mathrm{C}$ the ordered binary $L 1_{0}$ - MnPt phase was formed and pronounced Mn surface segregation was registered. An unreacted Fe layer remains in the film at these temperatures, dominating the materials magnetic properties. The following increase of the sample temperature up to $450{ }^{\circ} \mathrm{C}$ results in the incorporation of $\mathrm{Fe}$ to the $L 1_{0}-\mathrm{MnPt}$ structure and the additional formation of metastable bcc $\mathrm{Fe}_{3} \mathrm{Pt}$. Upon further annealing to $500{ }^{\circ} \mathrm{C}$, the $\mathrm{bcc} \mathrm{Fe}_{3} \mathrm{Pt}$ structure transforms into the paramagnetic fcc $\mathrm{Fe}_{3} \mathrm{Pt}$ structure resulting in a decrease of the saturation magnetization. The following rise in saturation magnetization obtained after annealing at $620{ }^{\circ} \mathrm{C}$ is related to the chemical $\mathrm{Ll}_{2}$ ordering of $\mathrm{Fe}_{3} \mathrm{Pt}$, which is ferromagnetic at room temperature. The final phase products of $L 1_{0}$ - FeMnPt and $L_{2}-\mathrm{Fe}_{3} \mathrm{Pt}$ are consistent with the initial elemental concentrations of the $\mathrm{Pt} / \mathrm{Mn} / \mathrm{Fe}$ trilayer, though the path of synthesis was rather unexpected.

\section{Acknowledgment}

This work was financially supported by the German Research Foundation (DFG Grant number AL618/34-1) and by the GINOP-2.3.2-15-2016-00041 project co-financed by the European Union and the European Regional Development Fund.

\section{References}

[1] Oleshkevych A., Zamani A., Kotenko I., Voloshko S., Sidorenko S., and Rennie A.R. 2012 J. Alloys Cmpd. 535108.

[2] Aboulfadl H., Gallino I., Busch R., and Múcklich F. 2016 J. Appl. Phys. 120195306.

[3] Srivastava A.K., Yu-Zhang K., Kilian L., Frigerio J.M., and Rivory J. 2007 J. Mater. Sci. 42185.

[4] Rothhaar U., Oechsner H., Scheib M., and Müller R. 2000 Phys. Rev. B 61974.

[5] Li J., Sha N., and Zhao Z. 2018 Appl. Surf. Sci. 454233.

[6] Hu B., Xu J., Wang J., Liu B., and Du B. 2018 Mater. Lett. 23251.

[7] Yao J., Zheng X., Cai W., and Sui J. 2017 J. Alloys Cmpd. 6951243.

[8] Desai N.D., Ghanwat B., Khot K.V., Mali S.S., Hong C.K., and Bhosale P.N. 2016 J. Mater. Sci. - Mater. Electron. 272385.

[9] Su L., Yu Y., Calo L., and Zhang Y. 2015 Nano Res. 82686.

[10] Oujja M., Martin-Garcia L., Rebollar E., Quesada A., Garcia M.A., Fernandez J.F., Marco J.F., Figuera J., and Castillejo M. 2018 Appl. Surf. Sci. 45219.

[11] Kim B.-H., Chung Y.-C. 2009 J. Appl. Phys. 106044304.

[12] Toinin J.P., Hoummada K., Bertoglio M., and Portavoce A. 2016 Scr. Mater. 1222. 
[13] Mohammadzadeh R., and Mohammadzadeh M.2018 J. Appl. Phys. 124035102.

[14] Feng Y., Liu M., Shi Y., Ma H., Li D., Li Y., Lu L., and Chen X. 2019 Prog. Nat. Sci. 29341.

[15] Panda R., Naik R., and Mishra N.C. 2019 J. Alloys Compd. 778819.

[16] Chakravarty S., Chirayath V.A., Gangavarapu A., Parida P., and Dasgupta A. 2015 J. Phys. D; Appl. Phys. 48305303.

[17] Pontes F.M., Pontes D.S.L., Leite E.R., Longo E., Chiquito A.J., Machado M.A.C., Pizani P.S., and Varela J.A. 2004 Appl. Phys. A 78349.

[18] Peng Y., Wang F., Wang Z., Alsayed A.M., Zhang Z., Yodh A.G., and Han Y. 2015 Nat. Mater. 14101.

[19] Katona G.L., Vladymyrskyi I.A., Makogon I.M., Sidorenko S.I., Kristaly F., Daroczi L., Csik A., Liebig A., Beddies G., Albrecht M., and Beke D.L. 2014 Appl. Phys. A 115203.

[20] Vladymyrskyi I.A., Gafarov A.E., Burmak A.P., Sidorenko S.I., Katona G.L., Safonova N.Y., Ganss F., Beddies G., Albrecht M., and Makogon Y.N. 2015 J. Phys. D: Appl. Phys. 49035003.

[21] Beke D.L., Kaganovskii Y., Katona G.L. 2018 Prog. Mater. Sci. 98625.

[22] Pavlova O.P., Verbitska T.I., Vladymyrskyi I.A., Sidorenko S.I., Katona G.L., Beke D.L., Beddies G., Albrecht M., and Makogon I.M. 2013 Appl. Surf. Sci. 266100.

[23] Yu S.Y., Li H.-B., Li W.L., Liu M., and Fei W.D. 2008 J. Magn. Magn. Mater. 320 L125.

[24] Wu Y.-C., Wang L.-W., and Lai C.-H.2007 Appl. Phys. Lett. 91072502.

[25] Gupta R., Medwai R., Sharma P., Mahapatro A.K. Annapoorni S. 2013 Superlattices Microstruct. 64408.

[26] Katona G.L., Safonova N.Y., Ganss F., Mitin D., Vladymyrskyi I.A., Sidorenko S.I., Makogon Iu.N., Beddies G., Albrecht M. and Beke D.L.2015 J. Phys. D: Appl. Phys. 48175001.

[27] Menshikov A.Z., Antropov V.P., Gasnikova G.P., Dorofeyev Y.A., and Kazantsev V.A. 1987 J. Magn. Magn. Mater. 65159.

[28] Xu D.B., Chen J.S., Zhou T.J., and Chow G.M. 2011 J. Appl. Phys. $10907 B 747$.

[29] Lai C.H. and Ho C.H. 2005 J. Appl. Phys. $9710 \mathrm{~J} 314$.

[30] Huang J.C.A., Chang Y.C., Yu C.C., Yao Y.D., Hu Y.M., and Fu C.M. 2003 J. Appl. Phys. 93 8173.

[31] Safonova N.Y., Riepp M., Klein O., and Albrecht M. 2017 J. Phys. Conf. Ser. 90312023.

[32] Meyer G. and Thiele J.-U. 2006 Phys. Rev. B 73214438.

[33] Manoharan E.A., Mankey., Hong Y.-K. 2017 J. Magn. Magn. Mater. 438111.

[34] Crisan O., Vasiliu F., Crisan A.D., Mercioniu I., Schinteie G., and Leca A. 2019 Mater. Charact. 152245. 
[35] Chiang C.C., Tsai W.C., Wang L.W., Hou H.C., Liao J.W., Lin H.J., Chang F.H., Kirby B.J., and Lai C.H. 2011 Appl. Phys. Lett. 99212504.

[36] Kraus W. and Nolze G. 1996 J. Appl. Crystallogr. 29301.

[37] Dollase W.A. 1986 J. Appl. Crystallogr. 19267.

[38] Toby B.H. 2006 Powder Diffr. 2167.

[39] Andrieu S., Fischer H.M., Traverse A., Piecuch M. 1997 J. Magn. Magn. Mat. 165185.

[40] Raub E. and Mahler W. 1955 Z. Metallkd. 46282.

[41] Ladwig P.F., Chang Y.A., Linville E.S., Morrone A., Gao J., Pant B.B., Schlutz A.E., and Mao S. 2003 J. Appl. Phys. 94979.

[42] Hsiao S.N., Chen S.K., Liu S.H., and Lee H.Y 2012 J. Appl. Phys. 111 07A313.

[43] Shiomi Y. 2018 AIP Advances 8085018.

[44] Mizoguchi T., Akimitsu M., and Chikazumi S. 1973 J. Phys. Soc. Jpn. 34932. 